\title{
Monoacylglycerol lipase inhibition attenuates acute and anticipatory nausea in rats
}

\section{Rachel I. Downey, Cheryl L. Limebeer, Heather I. Morris, and Linda A. Parker}

Department of Psychology, College of Social and Applied Human Sciences, University of Guelph, Guelph, ON Canada. Faculty supervisor: Dr. Linda Parker. For correspondence, please email: parkerl@uoguelph.ca.

\section{Abstract}

This study investigates the role of the endocannabinoid 2-arachidonyl glycerol (2-AG) in regulating acute and anticipatory nausea in rats using the conditioned gaping model. The animals were systemically pretreated with MJN110, a selective monoacylglycerol lipase (MAGL) inhibitor, to enhance endogenous levels of 2-AG. Acute nausea was assessed using the taste reactivity model in which a flavour, saccharin, was paired with the administration of the emetic agent, lithium chloride (LiCl). Anticipatory nausea was assessed using a model of contextually elicited conditioned gaping in which a context was paired with the emetic agent, LiCl. Results indicated that MJN110 at the $10.0 \mathrm{mg} \mathrm{kg}^{-1}$ and $20.0 \mathrm{mg} \mathrm{kg}^{-1}$ dosage significantly attenuated acute and anticipatory nausea, as displayed by the significant reduction in mean number of gapes. This suppression was mediated by $\mathrm{CB}_{1}$ receptor activation as displayed by reversal of such effects when MJN110 was coadministered with the $C_{1}$ receptor antagonist, SR 141716. The results suggest that enhancement of endogenous 2-AG levels by MAGL inhibition may have anti-emetic potential.

Keywords: 2-arachidonyl glycerol; monoacylglycerol lipase; endocannabinoid; nausea; conditioned gaping; $\mathrm{CB}_{1}$ receptor

\section{Introduction}

The sensation of nausea is understood to be a very distressful human experience as the feeling often extends for a prolonged duration of time (Parker et al. 2011). Although there are treatments available for vomiting, there are few effective treatments for nausea. This issue is especially meaningful for patients undergoing chemotherapy, which is known to produce nausea following treatment (acute nausea) as well as in anticipation of the treatment following a series of therapy sessions (anticipatory nausea). Following the establishment of anticipatory nausea, anti-emetic agents are almost completely ineffective as treatment (Hickok 2003). Thus the need for treatments to counter the expression of acute and anticipatory nausea is great.

\section{The endocannabinoid system}

Considerable evidence suggests that the endocannabinoid system regulates nausea and vomiting (see Parker et al. 2011 for review). The relatively recent discovery of the endocannabinoid system of the brain originally stems from the work conducted by Gaoni and Mechoulam (1964) in isolating the cannabis constituent, $\Delta^{9}$ - tetrahydrocannabinol $\left(\Delta^{9}-\mathrm{THC}\right)$, in 1964 . This finding allowed for the structure of the exogenous cannabinoid to be elucidated, its mechanism of action to be investigated, as well as synthetic analogues to be contrived to clinically assess its properties. Research has indicated that synthetic analogues of $\Delta^{9}$-THC, including nabilone and dronabinol, are more effective at reducing nausea than other available antiemetic treatments (Parker et al. 2011). In assessing the mechanism of action, Howlett and colleagues (1986) suggested that the actions of cannabinoids are receptormediated by revealing that they require the presence of a guanine nucleotide-binding protein complex, $\mathrm{G}_{\mathrm{i}}$, to inhibit adenylate cyclase activity. Shortly after, these $G$ protein coupled receptors (GPCR) were identified and found to be located both centrally and peripherally within the body (Devane et al. 1988; Munro et al. 1993). These receptors were termed the cannabinoid type $1\left(\mathrm{CB}_{1}\right)$ and cannabinoid type $2\left(\mathrm{CB}_{2}\right)$ receptors. $\mathrm{CB}_{1}$ receptors are found to be highly expressed and widely distributed in the brain whereas $\mathrm{CB}_{2}$ receptors are predominantly located in peripheral regions (Katona and Freund 2012).

The $\mathrm{CB}_{1}$ receptor has been shown to play a role in regulating nausea. The $\mathrm{CB}_{1}$ receptors are primarily located on the presynaptic neuron, facilitating the inhibition of both excitatory and inhibitory neurotransmitter release 
(Mechoulam and Parker 2012). As such, activation of $\mathrm{CB}_{1}$ receptors leads to a reduction in cyclic adenosine monophosphate (cAMP) concentrations, thus inhibiting cAMP-dependent protein kinase A (PKA) (Mechoulam and Parker 2012). This characteristic is essential in the regulation of nausea by cannabinoids.

The discovery of the $\mathrm{CB}_{1}$ and $\mathrm{CB}_{2}$ receptors stimulated further research on investigating potential endogenous ligands to these binding sites. Two endogenous cannabinoids (endocannabinoids) were found to bind to such receptors and were isolated and identified as $\mathrm{N}$-arachidonoylethanolamine (anandamide) and 2-arachidonylglycerol (2-AG) (Devane et al. 1992, Mechoulam et al. 1995). These ligands are lipid compounds that are unlike other common neurotransmitters that are stored in vesicles and released upon activation (Mechoulam and Parker 2012). Instead, endocannabinoids are synthesized where and when needed in both central and peripheral locations (Mechoulam and Parker 2012). Anandamide acts as a partial agonist at the $\mathrm{CB}_{1}$ receptor and as a weak agonist at the $\mathrm{CB}_{2}$ receptor (Wanga and Ueda 2009). In contrast, 2-AG has been indicated to have a high binding affinity for both of the $\mathrm{CB}_{1}$ and $\mathrm{CB}_{2}$ receptors (Sugiura et al. 1999). It should be noted that the mechanism by which 2-AG acts upon the $\mathrm{CB}_{1}$ receptor is of central interest in the current research, so a more advanced description will be applied here.

The synthesis of 2-AG occurs in the postsynaptic neuron through the hydrolysis of glycerophospholipid, an arachidonic acid-containing compound, by the enzyme phospholipase $\mathrm{C}$ (PLC) to produce $\mathrm{S}_{\mathrm{N}}-1$-acyl-2 arachidonylglycerol (Wanga and Ueda 2009). The enzyme diacylglycerol lipase (DAGL) then hydrolyzes this to produce $2-\mathrm{AG}$, which travels in a retrograde fashion across the synapse, binds to the $\mathrm{CB}_{1}$ receptor, and activates the Gprotein coupled $\mathrm{CB}_{1}$ receptor to lead to a reduction in neurotransmitter release (Wanga and Ueda 2009; Mechoulam and Parker 2012). Following receptor activation, 2-AG is rapidly taken up into the presynaptic neuron where it is then hydrolyzed by the enzyme monoacylglycerol lipase (MAGL) into glycerol and arachidonic acid (Niphakis et al. 2013). Recently, in vivo research conducted by Niphakis and colleagues (2013) demonstrated that the NHS carbamate, MJN110, is a potent and selective inhibitor of MAGL. Therefore, suppressing 2-AG hydrolysis via MAGL inhibition enhances levels of 2-AG and subsequently prolongs its activity (Niphakis et al. 2013).

\section{Serotonin and the endocannabinoid system}

A key finding in linking the role of the endocannabinoid system to nausea and vomiting was that blockage of the serotonin (5-HT) subtype receptor, 5- $\mathrm{HT}_{3}$, suppresses drug-induced emesis in the shrew (Torii, Saito, and Matsuki 1991). This finding is consistent with the way that a currently available treatment, ondansetron, controls vomiting in chemotherapy patients by acting as a $5-\mathrm{HT}_{3}$ receptor antagonist (Parker et al. 2011). As previously mentioned, $\mathrm{CB}_{1}$ agonism by synthetic analogues of $\Delta^{9}$-THC has been demonstrated to attenuate the sensation of nausea. Since agonists acting upon the $\mathrm{CB}_{1}$ receptor inhibit subsequent neurotransmitter release, it is theorized that the endocannabinoid system interacts with the serotonergic system in the control of emesis. Specifically, it is postulated that $\mathrm{CB}_{1}$ activation directly suppresses 5 -HT release and subsequent activity to reduce nausea and vomiting. Support for this claim is evident in research conducted by Nakazi and colleagues (2000) who demonstrated that presynaptic $\mathrm{CB}_{1}$ receptor activation inhibits the release of serotonin in the mouse brain. It is further postulated that cannabinoids inhibit $5-\mathrm{HT}_{3}$ receptors noncompetitively by binding to an allosteric site, evidenced by the inability of the cannabinoid agonist, WIN 55,212, to displace the 5- $\mathrm{HT}_{3}$ antagonist from its binding site (Barann et al. 2002, Parker et al. 2011). Additional evidence to support this theory is that SR141716, a $\mathrm{CB}_{1}$ receptor antagonist/inverse agonist, produces emesis in the least shrew and is mediated by enhancement of forebrain 5-HT concentrations and turnover (Darmani et al. 2003). Further supporting this theory is the presence of both serotonergic and cannabinoid receptors in neural regions associated with emesis, including the dorsal vagal complex (DVC) and the visceral insular cortex (VIC) (Parker et al. 2011; Tuerke et al. 2012). Together, these findings associating neural serotonin concentrations and the endocannabinoid system in mediating emesis can allow for further investigation of the clinical applications of such systems in regulating nausea.

\section{Conditioned gaping: A selective measure of nausea in rats}

As rats cannot biologically vomit, they act as an appropriate model in the investigation of nausea. The predominant measure previously used to investigate nausea in rats was through the conditioned taste avoidance (CTA) model. In this paradigm, a neutral stimulus, a flavour, is paired with an unconditioned stimulus, an emetic agent, to establish conditioned avoidance of the flavour. However, this method has shown to be a nonselective measure of nausea. Specifically, research has demonstrated that rewarding drugs can also produce the CTA response (Parker et al. 2011). Although this is a paradoxical finding, it is suggested that from an evolutionary perspective, rats learn to avoid flavours paired with any change in their hedonic state because they cannot vomit (Parker et al. 2011). An additional measure to assess the validity of this animal model of nausea is to evaluate whether the established taste avoidance can be interfered with by anti-emetic agents. Previous research has demonstrated that anti-emetic drugs do not inhibit the establishment of this learned taste avoidance, further supporting its unsuitability in assessing nausea (Parker et al. 2011).

It is thus largely evident that an additional model, which more selectively assesses nausea in rats, must be implemented. As such, the conditioned gaping response has been investigated and found to be a more selective measure of nausea. In this model, rats display a conditioned gaping reaction following the conditioning of a flavour or a context 
paired with an emetic agent. The conditioned gaping response is characterized by a large opening of the mouth with simultaneous retraction of the corner of the mouth to expose the lower incisors. Evidence to support the validity of this model arises from research demonstrating that only emetic agents are able to produce conditioned gaping (Parker 2009). Furthermore, research has revealed that anti-emetic agents can successfully interfere with the establishment of conditioned gaping, inhibiting such responses in being displayed (Parker 2009). Since conditioned gaping has been recognized as an appropriate measure for assessing nausea, it is used in this study to investigate both acute and anticipatory nausea.

\section{Animal model of acute nausea: Taste reactivity}

Acute nausea can be measured using the taste reactivity (TR) model. In this procedure, rats are conditioned to associate a neutral flavor, saccharin, with the unconditioned stimulus, an emetic agent (lithium chloride [ $\mathrm{LiCl}]$ ) to establish the conditioned gaping response (Grill and Norgren 1978). Prior to the single conditioning trial, the potential of an anti-emetic agent to suppress the establishment of conditioned gaping by suppressing $\mathrm{LiCl}$-induced nausea is assessed. If the drug reduces nausea, then the rats display fewer gapes in a subsequent drug-free test. This TR paradigm is used as an animal model to clinically evaluate anti-emetic drugs in reducing acute nausea.

\section{Animal model of anticipatory nausea: Contextually-elicited conditioned gaping}

Anticipatory nausea (AN) can be implemented to assess contextually-elicited conditioned gaping. In this procedure, rats are conditioned to associate a neutral stimulus, a context, with the unconditioned stimulus, an emetic agent $(\mathrm{LiCl})$, to establish the conditioned gaping response (Limebeer et al. 2008). Following four pairings of the context with $\mathrm{LiCl}$, the potential of an anti-emetic agent to suppress the expression of gaping elicited by the context in the absence of $\mathrm{LiCl}$ is assessed. This model clinically evaluates the anti-emetic potential of drugs in reducing anticipatory nausea.

\section{Hypotheses}

This study investigates the potential of suppression of 2-AG hydrolysis via MAGL inhibition to suppress the establishment and expression of conditioned gaping in the acute and anticipatory models of nausea, respectively. It was hypothesized that: (1) enhancing 2-AG levels by MAGL inhibition would attenuate the establishment of acute nausea; (2) potentiating levels of 2-AG by MAGL inhibition would decrease the expression of anticipatory nausea; and (3) 2-AG displays these anti-emetic effects via its action at the $\mathrm{CB}_{1}$ receptor.

\section{Methods}

\section{Subjects}

The subjects were male Sprague-Dawley rats (St. Constant, Quebec) weighing 250-300 g at the beginning of the experiments. The rats were either single-housed or pairhoused in shoebox cages and were maintained on a reverse light dark cycle (7:00 AM lights on; 7:00 PM lights off) with free access to food (Highland Rat Chow [8640]) and water, except during testing. Following experimental testing, animals were either euthanized using $\mathrm{CO}_{2}$ or through a decapitation procedure. All animal care and experimental procedures complied with the Canadian Council on Animal Care and were approved by the Animal Care Committee at the University of Guelph.

\section{Drug treatments}

All injections were administered intraperitoneally (ip). The emetic agent, $\mathrm{LiCl}$, was prepared in a $0.15 \mathrm{M}$ solution with sterile water and injected at a volume of $20.0 \mathrm{~mL}$ $\mathrm{kg}^{-1}\left(127.2 \mathrm{mg} \mathrm{kg}{ }^{-1}\right.$ dose). MJN110 was prepared in concentrations of $5.0 \mathrm{mg} \mathrm{mL}$ (injected at a volume of $1.0 \mathrm{~mL} \mathrm{~kg}^{-1}$ ), $10.0 \mathrm{mg} \mathrm{mL}^{-1}$ (injected at a volume of $1.0 \mathrm{~mL}$ $\mathrm{kg}^{-1}$ ), and $20.0 \mathrm{mg} \mathrm{mL}^{-1}$ (injected at a volume of $2.0 \mathrm{~mL} \mathrm{~kg}$ $\left.{ }^{1}\right)$. SR141716 was prepared in a concentration of $1.0 \mathrm{mg}$ $\mathrm{mL}^{-1}$ and injected at a volume of $1.0 \mathrm{~mL} \mathrm{~kg}^{-1}$. The drugs MJN110 (Cravatt BF Laboratory) and SR141716 (Tocris) were first dissolved in ethanol and Tween80 was added based upon a final drug concentration with a ratio of 1:9 (Tween80:saline). The ethanol was evaporated off using a nitrogen stream and the saline was then added.

\section{Behavioural apparatus}

Taste reactivity chamber. During the adaptation, conditioning, and testing phases in the assessment of acute nausea, rats were individually placed in a clear Plexiglas chamber $(29 \times 29 \times 10 \mathrm{~cm})$ that rested on a glass plated table and covered with a black lid. The room was dark during each of the phases, with the chamber being illuminated by placing two $50 \mathrm{~W}$ lightbulbs on either side of the table. To ensure optimal viewing of the rats' orofacial responses, a mirror was placed at a 45 degree angle beneath the glass table. A Sony video camera (Handy Cam) was placed directly in front of the table that was attached to a computer to further warrant a reliable evaluation of the rats' orofacial responses. In order to allow for the infusion of a fluid into the animals' mouths, the rats were surgically implanted with an intraoral cannula as described by Limebeer and Parker (2000). Prior to being placed into the chamber, the intraoral cannulas were attached to an infusion line that was correspondingly attached to an infusion pump. The infusion pump was fixed to deliver the particular fluid at a rate of $1 \mathrm{~mL} \mathrm{~min}^{-1}$. The recorded videos were later scored using "The Observer" event recording software (Noldus Inc.). 
Anticipatory nausea chamber. In assessing anticipatory nausea, the rats were placed in the same context, a black Plexiglas chamber $(22.5 \times 26 \times 20 \mathrm{~cm})$ that rested on a glass plated table, over a series of conditioning trials and during the testing phase. The room containing the AN chamber was located in a separate room from the TR chamber. The room was once again dark during each of the phases, with the chamber being illuminated by placing two $50 \mathrm{~W}$ lightbulbs on either side of the table. To facilitate in the optimal viewing of the ventral surface of the rat, a mirror at a 45 degree angle was placed beneath the table. A Sony video camera (Handy Cam) was placed directly in front of the table to videotape the rats' orofacial responses displayed on the mirror during the testing phase. The recorded videos were later scored using "The Observer" event recording software (Noldus Inc.).

Activity chamber. To assess the animals' locomotor behaviour, the rats were placed in a white Plexiglas activity chamber $(60 \times 25 \times 25 \mathrm{~cm})$. The location of the room containing the activity chamber was separate from both of the rooms containing the TR and AN chambers. The room was dark and was illuminated by placing a red light above the chamber. A video camera was mounted on an extension pole to allow for the locomotor activity of each rat to be assessed through a computer analysis of distance $(\mathrm{cm})$ traveled using the Ethovision software program (Noldus Inc.).

\section{Behavioural procedures}

Experiment 1: Effect of MAGL inhibition on LiClinduced acute nausea and conditioned taste avoidance. A total of 40 Sprague-Dawley rats were used to assess the effect of enhancing endogenous $2-A G$ levels via MAGL inhibition on the establishment of acute nausea. Upon arrival, the rats were handled and weighed for three consecutive days prior to surgical implantation of intraoral cannulas according to the procedure described by Limebeer et al. (2010). Following surgery, the rats were monitored for three days to ensure proper recovery prior to the conduction of any experimental procedures. Each rat then received an adaptation trial, a conditioning trial, and a TR test trial. During the adaptation trial, the rats were habituated to the TR chamber and the infusion procedure by being placed into the chamber for one minute, followed by a two minute infusion of sterile water at a rate of $1.0 \mathrm{~mL} \mathrm{~min}{ }^{-1}$.

On the conditioning trial, 24 hours after the adaptation trial, the rats were randomly assigned to one of five drug treatments: Veh (n=9), MJN110 (5.0 mg kg $\left.{ }^{-1}\right) \quad(\mathrm{n}=7)$, MJN110 (10.0 mg kg-1) (n=8), MJN110 (20.0 mg kg $\left.\mathrm{mg}^{-1}\right)$ $(\mathrm{n}=8)$, or MJN110 (10.0 mg kg-1) plus SR (1.0 mg kg-1) $(n=8)$. The treatments were administered two hours prior to the conditioning trial to allow for the accumulation of central 2-AG (Niphakis et al. 2013), except for the group that was injected with MJN110 plus SR, in which the injection of MJN110 (10 $\mathrm{mg} \mathrm{kg}^{-1}$ ) was administered 90 minutes prior to the injection of SR14716 (1.0 mg kg-1), followed by 30 minutes until the conditioning trial. On the conditioning trial, the rats were placed into the chamber for one minute and subsequently received an infusion of $0.1 \%$ saccharin $(1.0 \mathrm{~mL}$ $\min ^{-1}$ for two minutes). Orofacial responses were video recorded. Immediately following the time in the TR chamber, the rats were ip injected with $\mathrm{LiCl}(0.15 \mathrm{M}$ at a volume of $20.0 \mathrm{mg} \mathrm{kg}^{-1}$ ) and were then returned to their home cages. 72 hours after the conditioning trial, the rats received a drug-free test trial. During the test, the rats were placed into the TR chamber for one minute and were then re-exposed to an infusion of saccharin for two minutes. Their orofacial responses were videotaped and later scored to quantify the number of gapes. In order to assess CTA, the rats were water deprived for a period of 16 hours. During the CTA procedure, the rats were given two bottles, one containing saccharin and the other containing water, and consumption was measured over a period of 6 hours.

Experiment 2: Effect of MAGL inhibition alone and co-administered with a $\mathbf{C B}_{1}$ receptor inverse agonist/antagonist on $\mathrm{LiCl}$-induced anticipatory nausea and locomotor activity. A total of 34 Sprague-Dawley rats were used to assess the effect of 2-AG enhancement via MAGL inhibition on the expression of anticipatory nausea. Upon arrival, the rats were handled and weighed for three consecutive days to ensure healthy growth prior to any experimental procedures being conducted. Each rat received four conditioning trials, with 72 hours between trials. During each conditioning trial, each rat was ip injected with the emetic agent, $\mathrm{LiCl}\left(0.15 \mathrm{M}\right.$ at a volume of $\left.20.0 \mathrm{mg} \mathrm{kg}^{-1}\right)$, and were immediately placed into the AN chamber for 30 minutes. The test trial took place 72 hours after the fourth conditioning trial. For the test trial, the rats were randomly assigned into one of four drug groups: Veh-Veh $(n=10)$, MJN110 (10.0 mg kg-1)-Veh (n=8), MJN110 (20.0 mg kg-1)Veh $(\mathrm{n}=8)$, or MJN110 (10.0 mg kg-1)-SR (1.0 mg kg-1) $(\mathrm{n}=8)$. Pretreatment 1 consisted of either Veh or MJN110 at $10.0 \mathrm{mg} \mathrm{kg}^{-1}$ or $20.0 \mathrm{mg} \mathrm{kg}{ }^{-1}$, whereas pretreatment 2 consisted of either Veh or SR141716 $\left(1.0 \mathrm{mg} \mathrm{kg}^{-1}\right)$. The rats received pretreatment 190 minutes prior to receiving pretreatment 2, whereas pretreatment 2 was administered 30 minutes before placement into the AN chamber. Drug administration with MJN110 therefore occurred at a cumulative time period of 2 hours prior to being placed in the AN chamber to allow for the accumulation of central 2-AG concentrations.

During the test, the rats were ip injected with saline (20 $\mathrm{mg} \mathrm{kg}^{-1}$ ) and placed in the AN chamber for 5 minutes. Rats were observed for 5 minutes as opposed to the 30 minutes used during conditioning trials as previous experiments have shown that rats display the most contextually-elicited gaping reactions in this time period (Limebeer et al. 2008). The orofacial responses were videotaped and were later scored to quantify the number of gapes. Following the AN test trial, the rats were immediately placed in the activity chamber for a period of 15 minutes to analyze their locomotor behaviour via videotracking. Immediately following the activity analysis, the rats were euthanized via a decapitation procedure and the VIC was removed from their brains, frozen, and sent to Aron Lichtman at Virginia 
Commonwealth University for endocannabinoid analysis.

\section{Data analyses}

In Experiment 1, to determine the role of MAGL inhibition in regulating acute nausea, the mean number of gapes was entered into a one-way analysis of variance (ANOVA). In order to compare how observed gapes differed during the test trial among pretreatment groups, subsequent post-hoc Bonferroni tests were computed (Groups: Veh, MJN110: $5.0 \mathrm{mg} \mathrm{kg}^{-1}, 10.0 \mathrm{mg} \mathrm{kg}^{-1}, 20.0 \mathrm{mg}$ $\mathrm{kg}^{-1}, 10.0 \mathrm{mg} \mathrm{kg}^{-1}$ plus SR $1.0 \mathrm{mg} \mathrm{kg}{ }^{-1}$ ). Additionally, to determine if MAGL inhibition had an effect on CTA, the ratio of the volume of saccharin consumed to the volume of water consumed over the cumulative 6 hours of testing following Experiment 1 was entered into a one-way ANOVA (Groups: Veh, MJN110: $5.0 \mathrm{mg} \mathrm{kg}^{-1}, 10.0 \mathrm{mg} \mathrm{kg}^{-1}, 20.0 \mathrm{mg}$ $\mathrm{kg}^{-1}, 10.0 \mathrm{mg} \mathrm{kg}^{-1}$ plus SR $1.0 \mathrm{mg} \mathrm{kg}^{-1}$ ).

In Experiment 2, in order to determine the effects of the pretreatments in regulating anticipatory nausea and locomotor activity, the mean number of gapes and the mean distance $(\mathrm{cm})$ travelled were entered into a one-way ANOVA, respectively (Groups: Veh-Veh, MJN110 (10.0 mg $\left.\mathrm{kg}^{-1}\right)$-Veh, MJN110 (20.0 mg kg-1)-Veh, MJN110 (10.0 mg $\left.\mathrm{kg}^{-1}\right)$-SR $\left(1.0 \mathrm{mg} \mathrm{kg}^{-1}\right)$. Subsequent post-hoc Bonferroni tests were computed.

\section{Results}

\section{Experiment 1: Effect of MAGL inhibition on LiCl-induced acute nausea and conditioned taste avoidance}

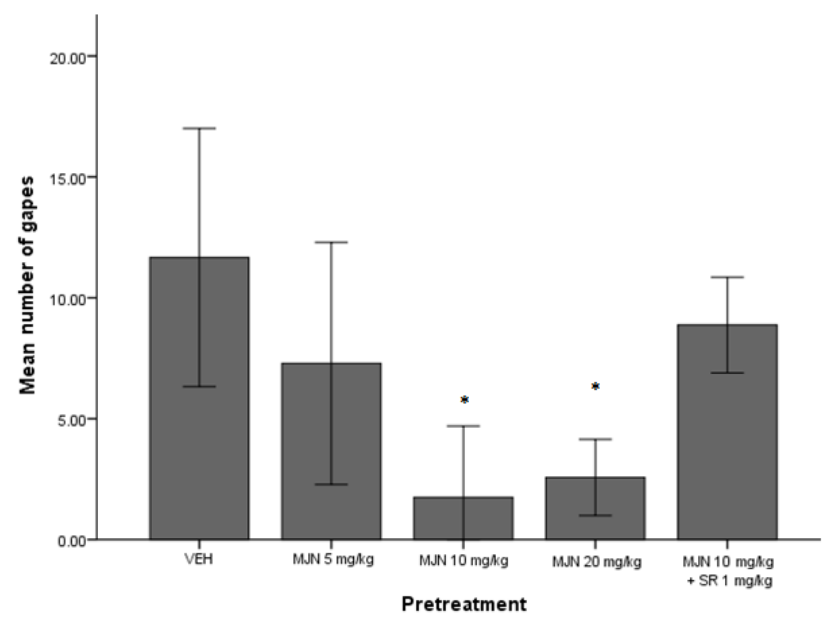

Figure 1. Mean ( \pm SEM) number of gapes displayed during the 3 minute testing period elicited by $20 \mathrm{~mL} \mathrm{~kg}^{-1}$ of $0.15 \mathrm{LiCl}$-paired $0.1 \%$ saccharin in rats in Experiment 1. The various groups received different pretreatments prior to test, including: VEH (n=9), MJN110 at doses $5.0 \mathrm{mg} \mathrm{kg}^{-1}(\mathrm{n}=7)$, $10.0 \mathrm{mg} \mathrm{kg}^{-1}(\mathrm{n}=8), 20.0 \mathrm{mg} \mathrm{kg}^{-1}(\mathrm{n}=8)$, or MJN110 at $10.0 \mathrm{mg} \mathrm{kg}^{-1}$ plus SR $1.0 \mathrm{mg} \mathrm{kg}^{-1}(\mathrm{n}=8)$. The asterisks $\left(^{*}\right)$ indicate that groups pretreated with the $10.0 \mathrm{mg} \mathrm{kg}^{-1}$ and $20.0 \mathrm{mg} \mathrm{kg}^{-1}$ doses of MJN110 gaped significantly less than the Veh group $(p<0.01)$.
TR test. Systemic administration of MJN110 dosedependently interfered with the establishment of nausea as indicated by the modulation of gaping reactions elicited by the pairing of $\mathrm{LiCl}$ with saccharin, as shown in Figure 1. The results revealed a significant main effect of pretreatment, $\mathrm{F}(4,35)=5.25, \mathrm{p}=0.002$. Further investigation of this main effect through Bonferonni post-hoc analyses demonstrated that gaping reactions during the test trial differed significantly between pretreatment conditions. Specifically, both the $10.0 \mathrm{mg} \mathrm{kg}^{-1}$ and $20.0 \mathrm{mg} \mathrm{kg}$-1oses of MJN110 significantly reduced observed gaping in comparison to the Veh group ( $p$ 's $<0.01$ ). It was also revealed that the MJN110SR group gaped significantly more than the MJN110 group at the doses of $10.0 \mathrm{mg} \mathrm{kg}^{-1}(\mathrm{p}<0.05)$ and $20.0 \mathrm{mg} \mathrm{kg}^{-1}$ $(\mathrm{p}<0.05)$, but did not differ significantly from the Veh group $(\mathrm{p}=0.287)$.

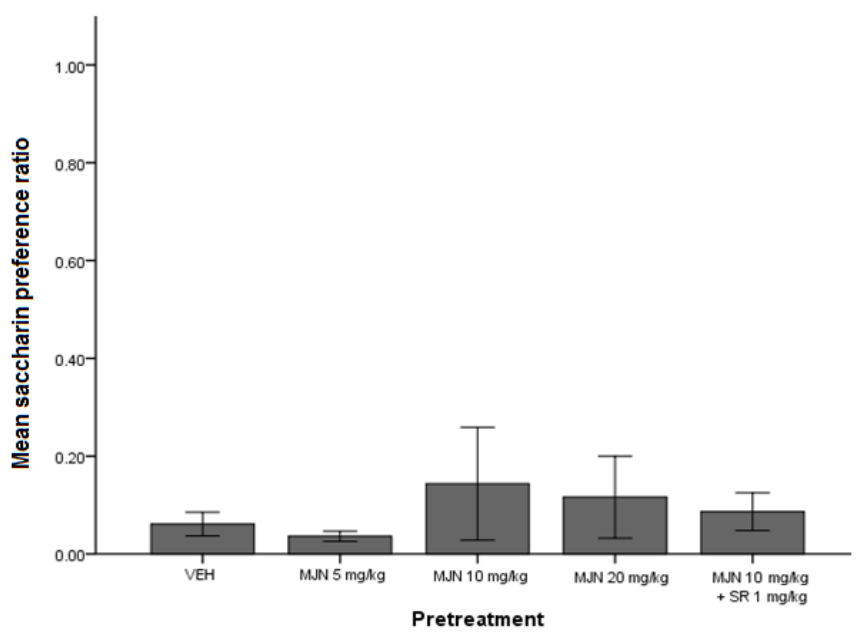

Figure 2. Mean ( \pm SEM) ratio of consumed bottle content (saccharin to water) over the cumulative 6 hour testing period following Experiment 1. The various groups received different pretreatments prior to test, including: $\operatorname{VEH}(\mathrm{n}=9)$, MJN110 at doses $5.0 \mathrm{mg} \mathrm{kg}^{-1}(\mathrm{n}=7), 10.0 \mathrm{mg} \mathrm{kg}^{-1}(\mathrm{n}=8), 20.0$ $\mathrm{mg} \mathrm{kg}^{-1}(\mathrm{n}=8)$, or MJN110 at $10.0 \mathrm{mg} \mathrm{kg}^{-1}$ plus SR $1.0 \mathrm{mg} \mathrm{kg}^{-1}(\mathrm{n}=8)$. There were no significant differences between the groups in the conditioned avoidance test.

Conditioned taste avoidance test. Statistical analysis of the CTA test revealed that none of the pretreatments modified the strength of the LiCl-induced saccharin taste avoidance, $F(4,35)=1.70, p=0.16$. Figure 2 presents the mean $( \pm$ SEM) ratio of consumed bottle content (saccharin to water) over the cumulative 6 hour testing period following Experiment 1. 
Experiment 2: Effect of MAGL inhibition alone and coadministered with a $\mathrm{CB}_{1}$ receptor antagonist on $\mathrm{LiCl}$ induced anticipatory nausea and locomotor activity

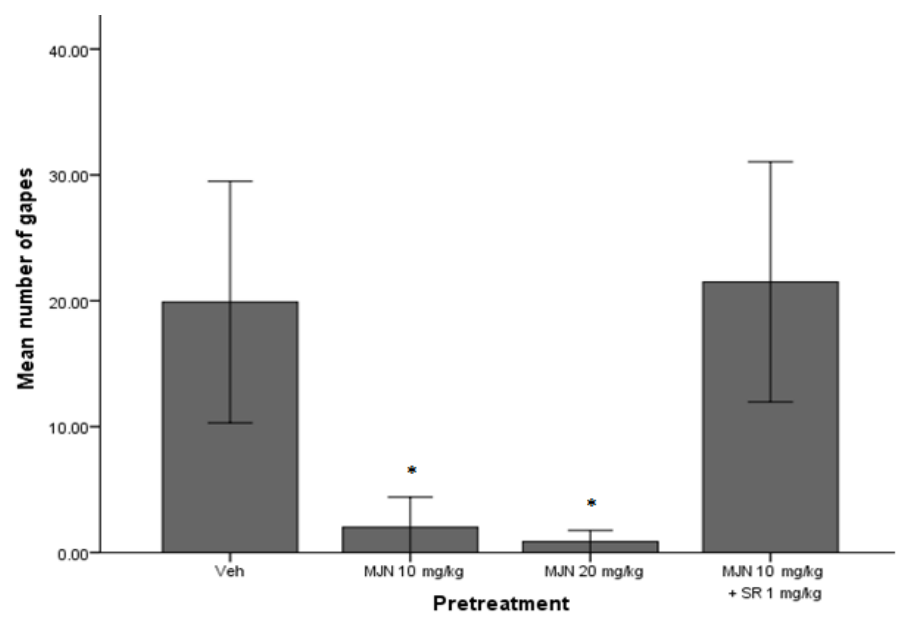

Figure 3. Mean ( \pm SEM) number of gapes displayed during the 5 minute testing period elicited by $20 \mathrm{~mL} \mathrm{~kg}^{-1}$ of $0.15 \mathrm{M} \mathrm{LiCl}$-paired context in rats in Experiment 2. The various groups received different pretreatments prior to test including Veh-Veh ( $n=10)$, MJN110 (10.0 mg kg-1)-Veh ( $n=8)$, MJN110 (20.0 mg kg-1)-Veh $(\mathrm{n}=8)$, or MJN110 (10.0 mg kg-1)-SR (1.0 mg kg-1) $(n=8)$. The asterisks $\left(^{*}\right)$ indicate that the groups pretreated with the $10.0 \mathrm{mg}$ $\mathrm{kg}^{-1}$ and $20.0 \mathrm{mg} \mathrm{kg}^{-1}$ dosage of MJN110-Veh gaped significantly less than the Veh-Veh group $(p<0.01)$.

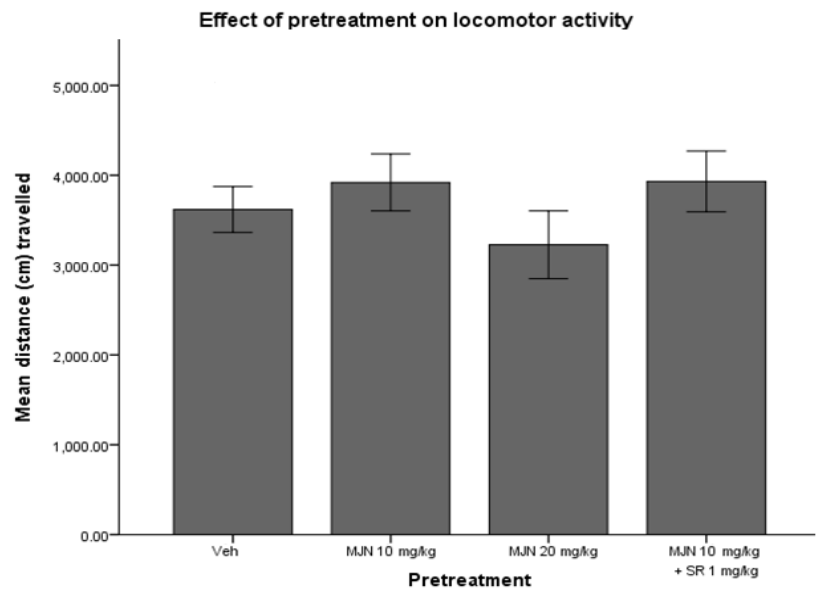

Figure 4. Mean ( \pm SEM) distance $(\mathrm{cm})$ travelled by rats during the $15 \mathrm{~min}$ activity test in Experiment 2 following pretreatment of Veh-Veh $(n=10)$, MJN110 (10.0 mg kg-1)-Veh ( $n=8)$, MJN110 (20.0 mg kg-1)-Veh ( $n=8)$, or MJN110 (10.0 mg kg-1)-SR $\left(1.0 \mathrm{mg} \mathrm{kg}^{-1}\right)(\mathrm{n}=8)$. The graph indicates that no groups differed significantly in locomotor activity when compared to VehVeh, therefore negating the potential of sedation as a function of MJN110 driving the suppression of anticipatory nausea.
AN test. Systemic administration of the MAGL inhibitor, MJN110, was found to interfere with the expression of nausea as displayed by the modulation of gaping reactions elicited by a LiCl-paired context seen in Figure 3. The statistical analysis revealed a significant main effect of pretreatment, $F(3,30)=9.10, p<0.001$. Further investigation of this effect was implemented through post-hoc Bonferroni tests, revealing that the MJN110 (10.0 mg kg$\left.{ }^{-1}\right)$-Veh and the MJN110 (20.0 mg kg-1)-Veh groups gaped significantly less than the Veh-Veh group (p's $<0.01$ ). It was also revealed the $\mathrm{CB}_{1}$ receptor antagonist, SR14716, reversed the anti-emetic effects of MJN110 at the $10.0 \mathrm{mg} \mathrm{kg}^{-1}$ dose, which indicates that this effect is $\mathrm{CB}_{1}$ mediated.

Activity test. The analysis of locomotor activity following the AN test revealed no significant differences in the groups when compared to the Veh-Veh group, as displayed by the one-way ANOVA, $\mathrm{F}(3,30)=1.02, \mathrm{p}=0.40$, therefore negating the potential of sedation as a function of MJN110 driving the suppression of anticipatory nausea. These results are shown in Figure 4.

\section{Discussion}

The study provides strong evidence to support the role of the endocannabinoid system in regulating nausea. More specifically, it was found that inhibition of the hydrolysis of 2-AG via the MAGL inhibitor, MJN110, at doses greater than $10.0 \mathrm{mg} \mathrm{kg}^{-1}$ (ip) attenuated acute and anticipatory nausea in rats, as displayed by the suppression of conditioned gaping produced by a $\mathrm{LiCl}$-paired flavour and $\mathrm{LiCl}$-paired context, respectively. The results of the present research largely compliment previous reports on the anti-emetic properties of cannabinoids. Specifically, the synthetic analogues of $\Delta^{9}$-THC, nabilone and dronabinol, have shown to be more effective treatments in suppressing nausea than other available anti-emetic treatments (Parker et al. 2011). Additionally, the cannabis constituent, cannabidiol (CBD), was shown to reduce both $\mathrm{LiCl}$-induced vomiting in the house musk shrew and LiCl-induced conditioned gaping in rats (Rock et al. 2012). Sticht and colleagues (2013) also provided meaningful insight to the anti-emetic properties of 2-AG via exogenous administration in the house musk shrew, which showed to be consistent with the current research on acute nausea. As well, 2-AG suppressed the establishment of LiCl-induced conditioned gaping in rats showing that it reduced acute nausea (Sticht et al. 2013). A growth in our understanding of the role that cannabinoids play in controlling nausea, including results from this study, calls for further research in this area.

The current findings also complement the literature that has shown that boosting the levels of anandamide by inhibition of FAAH reduces vomiting and nausea in these models. The enhancement of endogenous levels of anandamide via inhibition of its hydrolysis by URB597 was demonstrated to interfere with cisplastin- and nicotineinduced vomiting in the house musk shrew (Parker et al. 2009). As well, URB597 reduced both acute (Cross-Mellor 
et al. 2007) and anticipatory (Rock et al. 2008) nausea, both by a $\mathrm{CB}_{1}$-dependent mechanism of action. These findings indicate that both anandamide and 2-AG have anti-nausea properties by their action at the $\mathrm{CB}_{1}$ receptor.

As rats cannot biologically vomit, the conditioned gaping reaction acted as an appropriate model for exploring the anti-nausea effects of such endocannabinoids. More specifically, the TR test in Experiment 1 allowed for the assessment of the anti-nausea properties of MJN110 on acute nausea by suppressing the nausea produced by $\mathrm{LiCl}$ during conditioning. In Experiment 2, the contextually-elicited conditioned gaping model permitted the investigation of the anti-nausea potential of MJN110 by suppressing the expression of previously established conditioned nausea in the absence of $\mathrm{LiCl}$. The finding that MJN110 attenuated both the establishment and expression of conditioned gaping responses in rats provides evidence that 2-AG regulates both acute and anticipatory nausea.

Although previous research has found that the MAGL inhibitor, JZL184, is effective in reducing LiCl-induced vomiting in shrews by suppressing MAGL, it was relatively ineffective in suppressing acute nausea in rats assed by the TR test (Long et al. 2009; Sticht et al. 2012). However, unlike MJN110, JZL184 is relatively ineffective in suppressing MAGL in rat brains, but is effective in shrew and mouse brains (Long et al. 2009; Niphakis et al. 2013; Sticht et al. 2013). The current study therefore provides evidence for a novel MAGL inhibitor, MJN110, that potently and selectively inhibits 2-AG degradation in rats as well as mouse brains, while also suppressing conditioned gaping responses in rats (Niphakis et al. 2013).

The mechanism of action of 2-AG was also investigated by pairing MJN110 in Experiments 1 and 2 with the $\mathrm{CB}_{1}$ receptor antagonist/inverse agonist, SR141716. The antinausea effect of 2-AG during both acute and anticipatory nausea was shown to be $\mathrm{CB}_{1}$ dependent because coadministration of SR141716 reversed the suppressive effect of MJN110. This finding is consistent with previous reports pertaining to the mechanism of action of 2-AG, indicating a high affinity to the $\mathrm{CB}_{1}$ receptor (Sugiura et al. 1999). The reliability of this pharmacological finding can further be used to broaden our understanding of the role that such endocannabinoids as 2-AG play in controlling nausea.

The CTA test evaluated the strength of conditioned avoidance to the $\mathrm{LiCl}$-paired saccharin among pretreatment groups in Experiment 1. The data of the CTA test was analyzed as a ratio of the quantity of saccharin consumed to the quantity of water consumed over the cumulative 6 hour period of testing. Accordingly, the lower the preference ratio, the stronger the avoidance response. As the results of the CTA test indicated that there were no significant differences between pretreatments on the saccharin preference ratio, it can be inferred that MJN110 did not modify the strength of the LiCl-induced saccharin avoidance. This finding indicates that although MJN110 suppressed conditioned gaping reactions associated with both acute and anticipatory nausea, it did not affect the strength of conditioned taste avoidance to the LiCl-paired saccharin. This result is consistent with previous findings showing that anti-emetic drugs do not inhibit the establishment of conditioned taste avoidance, indicating that the conditioned gaping model is a more selective measure of nausea (Parker et al. 2011).

The results of the activity test revealed that the administered MJN110 treatments did not alter locomotor behaviour in any of the dosage groups. Therefore, the suppression of contextually-elicited conditioned gaping is not simply the result of a general suppression of locomotor activity. This also provides evidence to indicate that endocannabinoids have enhanced therapeutic potential over previously described strategies for controlling anticipatory nausea. Indeed, the most prevalent current treatment for AN in chemotherapy patients is the use of non-specific antianxiety drugs (benzodiazepines, such as lorazepam), which have sedating side effects that may limit their effectiveness in treating AN (Razavi et al. 1993; Malik et al. 1995). Some pharmacological agents used to control acute nausea and vomiting are also associated with negative side effects such as sedation. The antihistamine, cyclizine, has anti-emetic properties primarily used to counteract motion sickness and to treat the establishment of vomiting but has shown to lead to drowsiness (Palazzo and Strunin 1984). Similarly, the nonprescription drug Gravol ${ }^{\circledR}$ (dimenhydrinate) is used to prevent nausea and motion sickness, but is also associated with negative sedative properties (Young et al. 1988). Moreover, the use of dimenhydrinate as an anti-emetic treatment has been reported to build tolerance to its sedative characteristics, forming dependence towards the drug (Young et al. 1988). Since MJN110 effectively suppressed acute and AN without sedation, our findings suggest that elevation of 2-AG may be a more effective treatment for acute and anticipatory nausea in chemotherapy patients than those currently available.

Together, these findings suggest that the suppression of nausea results from the enhancement of endogenous 2-AG levels following MAGL inhibition, and that this effect is mediated via activation of the $\mathrm{CB}_{1}$ receptor. Prospective research investigating central administration of MJN110 will aid in strengthening the reliability of the current findings. More broadly, research investigating endocannabinoids can therefore be seen as a promising field for the discovery of better treatments to control for nausea, especially in its clinical application as a therapeutic agent against acute and AN for patients undergoing chemotherapy.

\section{Acknowledgements}

This work was supported by an operating grant from the Natural Sciences and Engineering Research Council of Canada (NSERC) to Linda Parker. 


\section{References}

Barann, M, Molderings G, Bruss M, Bonisch H, Urban BW, Gothert M. 2002. Direct inhibition by cannabinoids of human 5- $\mathrm{HT}_{3 \mathrm{~A}}$ receptors: Probable involvement of an allosteric modulatory site. British Journal of Pharmacology. 137:589-596.

Cross-Mellor SK, Ossenkopp KP, Piomelli D, Parker LA. 2007. Effects of the FAAH inhibitor, URB597, and anandamide on lithium-induced taste reactivity responses: a measure of nausea in the rat. Psychopharmacology (Berl.). 190(2): 135-143.

Darmani NA, Janoyan JJ, Kumar N, Crim JL. 2003. Behaviourally active doses of the $\mathrm{CB}_{1}$ receptor antagonist SR 141716A increase brain serotonin and dopamine levels and turnover. Pharmacology, Biochemistry and Behaviour. 75: 777-787.

Devane WA, Dysarz FA 3rd, Johnson MR, Melvin LS, Howlett AC. 1988. Determination and characterization of a cannabinoid receptor in rat brain. Molecular Pharmacology. 34: 605-13.

Devane WA, Hanus L, Breuer A, Pertwee RG, Stevenson LA, et al. 1992. Isolation and structure of a brain constituent that binds to the cannabinoid receptor. Science. 258: 1946-1949.

Grill HJ, Norgren R. 1978. The taste reactivity test. I. Mimetic responses to gustatory stimuli in neurologically normal rats. International Brain Research Organization. 24(2): 263-279.

Hickok JT, Roscoe JA, Morrow GR, King DK, Atkins JN, Fitch TR. 2003. Nausea and emesis remain significant problems of chemotherapy despite prophylaxis with 5-hydroxytryptamine-3 antiemetics. Cancer. 9: 2880-2886.

Howlett AC, Qualy JM, Khachatrian LL. 1986. Involvement of $\mathrm{Gi}$ in the inhibition of adenylate cyclase by cannabimimetic drugs. Molecular Pharmacology. 29: 307-313.

Katona I, Freund TF. 2012. The multiple functions of endocannabinoid signaling in the brain. Annual Review of Neuroscience. 35: 529-558.

Limebeer CL, Krohn JP, Cross-Mellor S, Litt DE, Ossenkopp KP, Parker LA. 2008. Exposure to a context previously associated with nausea elicits conditioned gaping in rats: A model of anticipatory nausea. Behavioural Brain Research. 187: 33-40.
Limebeer CL, Vemuri VK., Bedard H, Lang, ST, Ossenkopp, KP, Makriyannis A, Parker LA. 2010. Inverse agonism of cannabinoid $\mathrm{CB}_{1}$ receptors potentiates $\mathrm{LiCl}$-induced nausea in the conditioned gaping model in rats. British Journal of Pharmacology. 161: 336-349.

Limebeer CL, Abdullah RA, Rock EM, Imhof E, Wang K., Lichtman AH, Parker LA. 2013. Attenuation of anticipatory nausea in a rat model of contextually elicited conditioned gaping by enhancement of the endocannabinoid system. Psychopharmacology. DOI: 10.1007/S00213-013-3282-7.

Long JZ, Li W, Booker L, Burston JJ, Kinsley SG, Schlosburg JE, Pavon FJ, Serrano AM, Selley DE, Parsons LH, Lichtman AH, Cravatt BF. 2009. Selective blockade of 2-arachidonylglycerol hydrolysis produces cannabinoid behavioural effects. Nature Chemical Biology. 5(1): 37-44.

Malik IA, Khan WA, Qazilbash M, Ata E, Butt A, Khan MA. 1995. Clinical efficacy of lorazepam in prophylaxis of anticipatory, acute, and delayed nausea and vomiting induced by high doses of cisplatin. a prospective randomized trial. American Journal of Clinical Oncology. 18: 170-175.

Mechoulam R, Parker LA. 2012. The endocannabinoid system and the brain. Annual Review of Psychology. 64: 21-47.

Mechoulam R, Ben-Shabat S, Hanus L, Ligumsky M, Kaminiski NE, et al. 1995. Identification of an endogenous 2-monoglyceride, present in canine gut, that binds to cannabinoid receptors. Biochemical Pharmacology. 50: 83-90.

Munro S, Thomas KL, Abu-Shaar M. 1993. Molecular characterization of a peripheral receptor for cannabinoids. Nature. 365: 61-65.

Nakazi M, Bauer U, Nickel T, Kathmann M, Schlicker E. 2000. Inhibition of serotonin release in the mouse brain via presynaptic cannabinoid $\mathrm{CB}_{1}$ receptors.

Naunyn-Schmiedeberg's Archives of Pharmacology. 361: 19-24.

Niphakis MJ, Cognetta AB, Chang JW, Buczynski MW, Parsons LH, Byrne F, Burston JJ, Chapman V, Cravatt BF. 2013. Evaluation of NHS carbamates as a potent and selective class of endocannabinoid hydrolase inhibitors. ACS Chemical Neuroscience. 4(9): 1322- 1332. 
Palazzo MB, Strunin L. 1984. Anesthesia and emesis II: Prevention and management. Canadian Journal of Anesthesia. 31(4):407- 415.

Parker LA. 2009. Conditioned disgust, but not conditioned taste avoidance, may reflect conditioned nausea in rats. In: Reilly S, Schachtman TR, editors. Conditioned Taste Aversion: Behavioural and Neural Processes. Ontario (ON): Oxford University Press. p. 92-113.

Parker LA, Limebeer CL, Rock EM, Litt DL, Kwiatkowska M, Piomelli D. 2009. The FAAH inhibitor URB597 interferes with cisplastin- and nicotine-induced vomiting in the Suncus murinus (house musk shrew). Physiology \& Behaviour. 97: 121-124.

Parker LA, Rock EM, Limebeer CL. 2011. Regulation of nausea and vomiting by cannabinoids. British Journal of Pharmacology. 163: 1411-1422.

Razavi D, Delvaux N, Farvacques C, De Brier F, Van Heer C, Kaufman L, Derde MP, Beauduin M, Piccart M. 1993. Prevention of adjustment disorders and anticipatory nausea secondary to adjuvant chemotherapy: A double-blind, placebo-controlled study assessing the usefulness of alprazolam. Journal of Clinical Oncology. 11: 1384-1390.

Rock EM, Bolognini D, Limebeer CL, Cascio MG, AnaviGoffer S, Fletcher PJ, Mechoulam R, Pertwee RG, Parker LA. 2012. Cannabidiol, a nonpsychotropic component of cannabis, attenuates vomiting and nausea-like behaviour via indirect agonism of 5$\mathrm{HT}_{1 \mathrm{~A}}$ somatodendritic autoreceptors in the dorsal raphe nucleus. British Journal of Pharmacology. 165: 2620- 2634.

Rock EM, Limebeer CL, Mechoulam R, Piomelli D, Parker, LA. 2008. The effect of cannabidiol and URB597 on conditioned gaping (a model of nausea) elicited by a lithium-paired context in the rat. Psychopharmacology (Berl.). 196: 389-395.

Sticht MA, Long JZ, Rock EM, Limebeer CL, Mechoulam R, Cravatt BF, Parker LA. 2012. Inhibition of monoacylglycerol lipase attenuates vomiting in Suncus murinus and 2-arachidonyl glycerol attenuates nausea in rats. British Journal of Pharmacology. 165: 2425- 2435.

Sticht MA, Rock EM, Parker LA. 2013. 2arachidonoylglycerol interferes with lithiuminduced vomiting in the house musk shrew, Suncus murinus. Physiology \& Behaviour. 120: 228- 232.
Sugiura T, Kodaka T, Nakane S, Miyashita T, Kondo S, Suhara Y, Takayama H, Waku K, Seki C, Baba N, Ishima Y. 1999. Evidence that the cannabinoid $\mathrm{CB}_{1}$ receptor is a 2-arachodonylglycerol recptor: Structure-activity relationship of 2arachodonylglycerol, etherlinked analogues, and related compounds. Journal of Biological Chemistry. 274: 2794-2801.

Torii Y, Saito H, Matsuki N. 1991. Selective blockade of cytotoxic drug-induced emesis by $5-\mathrm{HT}_{3}$ receptor antagonists in Suncus Murinus. Japanese Journal of Pharmacology. 55: 107-113.

Tuerke KJ, Limebeer CL, Fletcher PJ, Parker LA. 2012. Double dissociation between regulation of conditioned disgust and taste avoidance by serotonin availability at the $5-\mathrm{HT}_{3}$ receptor in the posterior and anterior insular cortex. The Journal of Neuroscience. 32(40): 13709 -13717.

Wanga J, Ueda N. 2009. Biology of endocannabinoid synthesis system. Prostaglandins \& other Lipid Mediators. 89: 112-119.

Young GB, Boyd D, Kreeft J. 1988. Dimenhydrinate: evidence for dependence and tolerance. Canadian Medical Association Journal. 138(5): 437-438. 